\title{
Cardiovascular Safety Profile of Dapoxetine during the Premarketing Evaluation
}

\author{
Peter R. Kowey, ${ }^{1}$ Ramagopal V. Mudumbi, ${ }^{2}$ Joseph W. Aquilina ${ }^{2}$ and Peter M. DiBattiste ${ }^{2}$ \\ 1 Division of Cardiovascular Disease, Lankenau Hospital and Institute of Medical Research, Wynnewood, \\ Pennsylvania, USA \\ 2 Johnson \& Johnson Pharmaceutical Research \& Development, L.L.C., Raritan, New Jersey, USA
}

\section{Abstract}

\section{Introduction}

Premature ejaculation (PE) is a sexual dysfunction characterized by short intravaginal ejaculatory latency time, an inability to control or
The cardiovascular safety profile of dapoxetine, a novel selective serotonin reuptake inhibitor (SSRI) developed as an on-demand oral treatment for premature ejaculation (PE) in men, is evaluated. The cardiovascular assessment of dapoxetine was conducted throughout all stages of drug development, with findings from preclinical safety pharmacology studies, phase I clinical pharmacology studies investigating the effect of dapoxetine on QT/corrected QT (QTc) intervals in healthy men, and phase III, randomized, placebo-controlled studies evaluating the safety (and efficacy) of the drug. Preclinical safety pharmacology studies did not suggest an adverse electrophysiologic or hemodynamic effect with concentrations of dapoxetine up to 2-fold greater than recommended doses. Phase I clinical pharmacology studies demonstrated that dapoxetine did not prolong the QT/QTc interval and had neither clinically significant electrocardiographic effects nor evidence of delayed repolarization or conduction effects, with dosing up to 4-fold greater than the maximum recommended dosage. Phase III clinical studies of dapoxetine in men with PE indicated that dapoxetine was generally safe and well tolerated with the dosing regimens used $(30 \mathrm{mg}$ and $60 \mathrm{mg}$ as required). Events of syncope were reported during the clinical development program, with the majority occurring during study visits (on site) on day 1 following administration of the first dose when various procedures (e.g. orthostatic maneuvers, venipunctures) were performed, suggesting that the procedures contributed to the incidence of syncope. This was consistent with previous reports showing that these and similar factors contribute to or trigger vasovagal syncope. Findings of the dapoxetine development program demonstrate that dapoxetine is associated with vasovagal-mediated (neurocardiogenic) syncope. No other associated significant cardiovascular adverse events were identified. 
not been associated with any cardiovascular comorbidities or health risks. ${ }^{[4]}$

Dapoxetine is a novel selective serotonin reuptake inhibitor (SSRI) developed as an ondemand oral treatment for PE and has been granted marketing authorization for the treatment of PE in men aged 18-64 years in 15 countries (as of August 2010). ${ }^{[5,6]}$ The pharmacokinetics of dapoxetine (e.g. maximum plasma concentration $\left[\mathrm{C}_{\max }\right]$ and elimination half-life) are timeinvariant, and increases are in a dose proportional manner. The pharmacokinetics are unaffected by age, ethnicity, or single or multiple dosing (30 and $60 \mathrm{mg}$ ). Dapoxetine demonstrates rapid absorption and elimination with minimal accumulation following daily dosing, and is extensively metabolized by multiple enzymes. ${ }^{[7-9]}$

Other SSRI medications approved for the treatment of depression have been shown to delay ejaculation in patients being treated for depression $^{[10,11]}$ and are used as off-label treatment for $P E .^{[12,13]}$ In comparison with dapoxetine, other SSRI medications have relatively slower absorption, resulting in potentially longer periods of exposure and accumulation. SSRIs approved for the treatment of depression, anxiety, and other psychiatric conditions have infrequently been associated with reports of cardiovascular adverse events (e.g. arrhythmias, orthostatic hypotension, syncope). ${ }^{[14-16]}$ During premarketing clinical studies for these medications, adverse events, such as hypertension, tachycardia, and palpitations, were reported as more frequent events. ${ }^{[17-19]}$

Here, we describe the evaluation of the cardiovascular safety of dapoxetine by Johnson \& Johnson Pharmaceutical Research \& Development, L.L.C., ${ }^{[5]}$ including the background and rationale for studies at each phase of development. The cardiovascular assessment of dapoxetine was conducted throughout all stages of drug development. Guidelines from health authorities were followed when available. ${ }^{[20-23]}$

The key studies evaluating the cardiovascular safety of dapoxetine included the following: (i) preclinical safety pharmacology studies; (ii) phase I clinical pharmacology studies investigating the effect of dapoxetine on QT/corrected QT (QTc) intervals in healthy men; and (iii) phase II and III, randomized, placebo-controlled studies evaluating the safety (and efficacy) profile of dapoxetine. Here, we describe the findings from these investigations that characterize the cardiovascular safety profile of dapoxetine.

\section{Preclinical Safety Pharmacology Studies}

Preclinical safety pharmacology studies evaluated the pharmacodynamic effects of dapoxetine on physiologic functions that may have relevance to its safety in humans. ${ }^{[5]}$ Key findings from these studies, ${ }^{[5]}$ with potential implications for understanding the cardiovascular safety profile of dapoxetine, are reviewed here. Dapoxetine decreased membrane potassium current in the human ether-à-go-go related gene (hERG) transfected human embryonic kidney cell line with a $50 \%$ inhibitory concentration $\left(\mathrm{IC}_{50}\right)$ of $3.26 \mu \mathrm{M}$. In man, the $\mathrm{C}_{\max }$ after a $60 \mathrm{mg}$ dose (the highest therapeutic dose) is $427 \mathrm{ng} / \mathrm{mL}$, equivalent to dapoxetine $1.4 \mu \mathrm{mol} / \mathrm{L}$ in vitro. The ratio of the expected $\mathrm{C}_{\max }$ in man to the $\mathrm{IC}_{50}$ is thus about 2.3 , suggesting an acceptable therapeutic safety margin of dapoxetine. Other electrophysiologic effects included a significant decrease in the amplitude of the action potential in conditions of a normal rhythm, and bradycardia in Purkinje fibers isolated from laboratory rabbits exposed to dapoxetine $10 \mu \mathrm{mol} / \mathrm{L}$. These results indicate a blockade of sodium and calcium currents with high concentrations of dapoxetine in rabbit conduction tissue.

In the anesthetized guinea pig, there were no significant changes in the duration of PQ, QRS, or QTcB (corrected for heart rate) intervals compared with baseline intervals at total intravenous doses of dapoxetine up to $9.87 \mathrm{mg} / \mathrm{kg}$, yielding exposures as high as $4.0 \mu \mathrm{mol} / \mathrm{L} .^{[5]}$ At a total intravenous dose of $39.38 \mathrm{mg} / \mathrm{kg}$, dapoxetine increased the PQ interval and the QRS interval, but decreased the QTcB interval compared with baseline. There were also dose-dependent decreases in heart rate and increases in blood pressure (BP) at this very high exposure. No effects on QTc interval were observed in anesthetized dog, conscious dog, or monkey studies. ${ }^{[5]}$ 
In summary, preclinical safety pharmacology studies suggested that adverse electrophysiologic or hemodynamic effects are unlikely with concentrations of dapoxetine up to 2-fold greater than recommended doses.

\section{Phase I Clinical Pharmacology QT Interval Studies}

Regulatory guidelines ensure the clinical evaluation of QT/QTc interval prolongation and proarrhythmic potential for new drugs with systemic bioavailability. ${ }^{[20,23]}$ Based on these guidelines, several studies were performed to evaluate the effect of a range of single oral doses of dapoxetine on QT/QTc interval. Two studies were conducted in healthy adult male subjects $(\mathrm{n}=336)$ with dapoxetine 60,120 , and $240 \mathrm{mg}$, placebo, and oral moxifloxacin $400 \mathrm{mg}$ as a positive control to demonstrate assay sensitivity. ${ }^{[24]}$

In these studies, dapoxetine at doses up to 4-fold greater than the maximum recommended dose did not prolong the QT/QTc interval compared with placebo and had no clinically significant electrocardiographic effects. Moxifloxacin significantly increased QT and QTc intervals compared with placebo in both studies. These findings were consistent across all the correction methods used, while there was no dose response in the QT/QTc effect. At clinically relevant exposures, dapoxetine demonstrated no evidence of delayed repolarization or conduction effects. ${ }^{[24]}$

In the QT/QTc interval studies, most adverse events were of mild severity and no serious adverse events were reported. There was a single report of vasovagal syncope, which occurred 2 hours after the first dapoxetine dose at the time of the postdose blood collection. In the other 21 phase I studies, four cases of syncope were reported.

\section{Phase II, Randomized, Placebo- Controlled Studies}

Two phase II studies evaluated the safety and efficacy of a range of doses of dapoxetine (20-100 mg) in multicenter, placebo-controlled trials in healthy adult men with PE. Dapoxetine treatment was generally safe and well tolerated across the range of doses, with no notable cardiovascular-related safety events directly attributed to dapoxetine treatment. ${ }^{[25]}$ However, there was a pattern of higher overall adverse event incidence with dapoxetine $100 \mathrm{mg}$ compared with dapoxetine $60 \mathrm{mg}$ and placebo. The most common adverse events were nausea, dizziness, diarrhea, insomnia, headache, and nervousness. Adverse events occurred predominantly with the first dose of dapoxetine study drug administered, were graded as mild to moderate in severity, and judged to be treatment-related by the investigators. There were no clinically relevant mean changes in ECG or vital sign data.

\section{Phase III, Randomized, Placebo- Controlled Studies}

The cardiovascular safety analyses were performed in five phase III clinical studies that assessed the overall efficacy and safety of dapoxetine in 6081 men with PE. ${ }^{[6,26-30]}$ These multicenter, randomized, placebo-controlled studies were conducted with 30 and $60 \mathrm{mg}$ doses of dapoxetine. Four of the five placebo-controlled studies were conducted with the proposed dapoxetine dosing regimens (30 or $60 \mathrm{mg}$ as required), ${ }^{[26,28-30]}$ whereas one placebo-controlled study was conducted with dapoxetine $60 \mathrm{mg}$ as required or $60 \mathrm{mg}$ once daily. ${ }^{[27]}$ The phase III clinical studies are registered at ClinicalTrials.gov as NCT00229073, ${ }^{[26]}$ NCT00210613, ${ }^{[27]}$ NCT00210704, ${ }^{[28]}$ NCT00211107,, ${ }^{[29]}$ and NCT00211094. ${ }^{[29]}$

Overall, dapoxetine treatment was generally safe and well tolerated with the tested dosing regimens. The safety profile of dapoxetine was generally consistent across the clinical studies, with the adverse effects consistent with the SSRI class of drugs, although the incidence and severity varied. The most common adverse events were those associated with the gastrointestinal and nervous system organ classes, and reflected acute symptomatic events that were generally self-limiting and temporally related to dosing, reflecting tolerability rather than serious safety concerns. ${ }^{\text {[26-30] }}$

Special attention was given to cardiovascularrelated safety issues since syncope has been reported with marketed SSRIs ${ }^{[14-16]}$ and there were 
five cases of vasovagal syncope during dapoxetine phase I studies. During the initial two phase III clinical studies of dapoxetine, further cases of syncope were reported although, at the time, the occurrence appeared balanced among the placebo, $30 \mathrm{mg}$, and $60 \mathrm{mg}$ treatment groups ( 2 of 872 [0.2\%], 3 of 876 [0.3\%], and 2 of 870 [0.2\%] episodes, respectively). Holter monitoring and orthostatic maneuvers were implemented in later phase III studies to enhance detection of syncopal and presyncopal events, and to ensure that the clinical database contained relevant and robust information regarding the circumstances of the occurrence of syncope. ${ }^{[26-28]}$

Treatment-emergent adverse events associated with the cardiovascular system were evaluated from the pooled data from the five phase III studies $(n=6081) .{ }^{[26-30]}$ Table I provides the overall incidence and the adverse events reported in five or more dapoxetine-treated subjects. The overall incidence of cardiovascular adverse events appeared to be dose related, occurring in 5.2\% of patients receiving placebo, $7.7 \%$ receiving dapoxetine $30 \mathrm{mg}$ as required, $16 \%$ receiving $60 \mathrm{mg}$ as required, and $24.5 \%$ receiving $60 \mathrm{mg}$ once daily. The most common adverse event was dizziness, occurring in $2.2 \%, 5.8 \%, 10.9 \%$, and $14.9 \%$ of patients, respectively. Cardiovascular etiology is not the only cause for dizziness, and the rates of cardiovascular adverse events excluding dizziness were $3.4 \%, 2.2 \%, 6.3 \%$, and $12.2 \%$, respectively. Orthostatic hypotension was also seen in $1.3 \%$ of dapoxetine-treated subjects. Other cardiovascular-related adverse events were reported rarely with an overall frequency of $<1 \%$. Sixteen cases of syncope, ten coding to the preferred term 'syncope' and six as 'vasovagal syncope' in the Medical Dictionary for Regulatory Activities (MedDRA), were reported in the five phase III studies. In placebo- and dapoxetinetreated groups, the respective incidence was $0.11 \%$ and $0.19 \%$ for syncope, and $0.05 \%$ and $0.12 \%$ for vasovagal syncope, indicating a relative risk of about 2 with dapoxetine. These events

Table I. Cardiovascular adverse events occurring in five or more dapoxetine-treated subjects in five phase III placebo-controlled studies

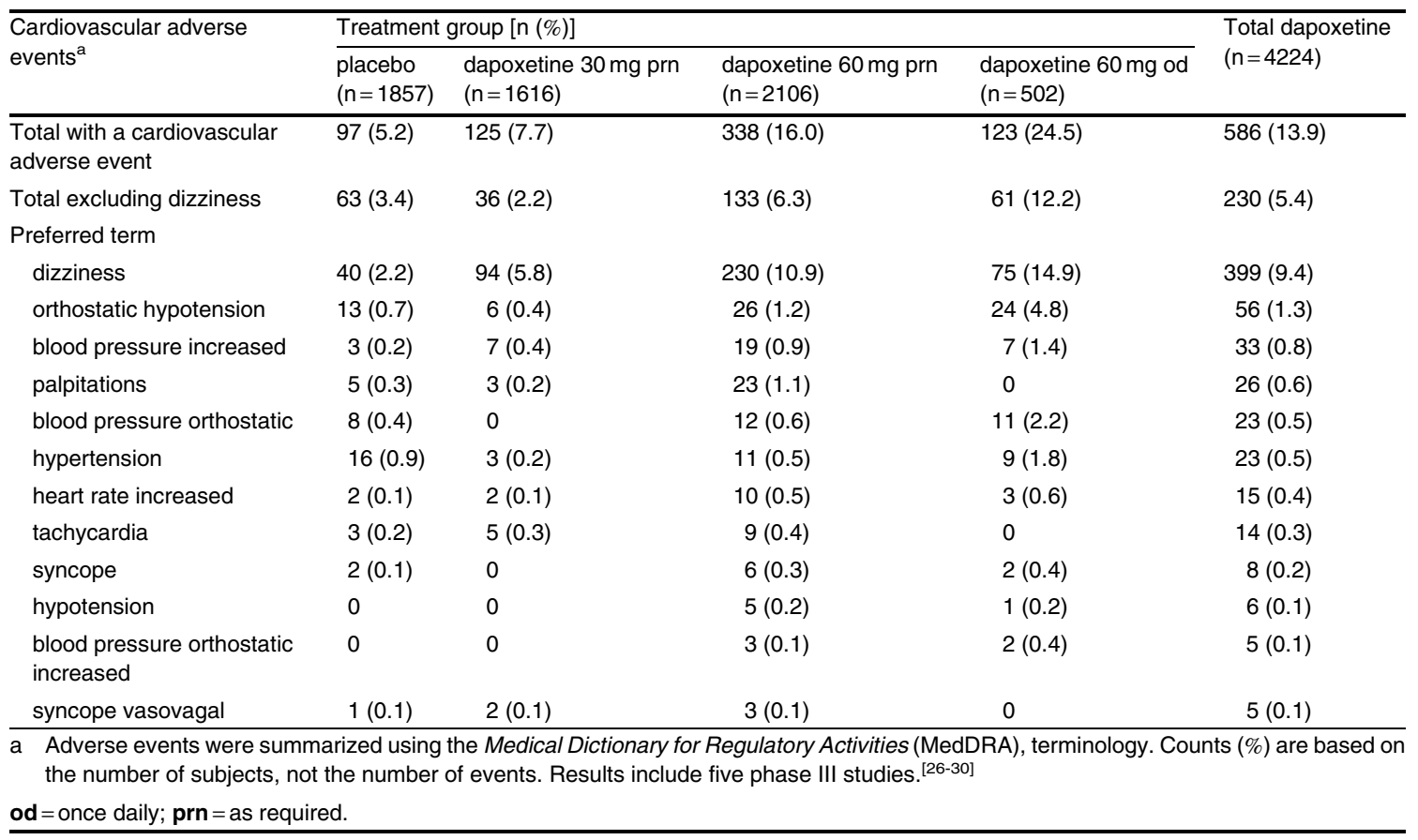


were further evaluated as part of a comprehensive assessment of syncope as described in section 6 .

\section{1 Holter Monitoring}

In three phase III studies, Holter ECG monitoring was performed on all subjects, beginning 10-30 minutes before and ending 3 hours after the first dose of study drug. ${ }^{[26-28]}$ The timing of Holter monitoring captured the time of expected dapoxetine peak concentrations, 1-3 hours following oral administration of doses in the range of $30-60 \mathrm{mg}{ }^{[8]}$ Subjects remained within the clinic during this time under direct supervision to monitor for any untoward events. Pooled Holter monitoring data from the three studies were evaluated for total incidence of abnormalities and number of events per hour during monitoring.

Table II summarizes the incidence of Holter monitoring abnormalities around the time of first dose in these three phase III studies. ${ }^{[26-28]}$ In 3353 patients, no symptomatic or sustained (continuous) tachyarrhythmias were detected. The incidence of Holter-detected non-sustained ventricular tachycardia was similar between dapoxetine-treated subjects and those who received placebo, suggesting that dapoxetine is not arrhythmogenic and that tachyarrhythmia is thus unlikely to be the underlying mechanism responsible for syncope seen in the dapoxetine clinical program. There was a statistically nonsignificant increase in the number of single ventricular and supraventricular ectopic beats in the dapoxetine groups, but this finding is not considered clinically meaningful, given the generally benign nature of ventricular ectopic beats occurring on their own in the absence of structural heart disease. ${ }^{[31]}$

\subsection{Orthostatic Measurements}

Orthostatic vital sign measurements were performed in three phase III studies on the first day of dosing to evaluate whether orthostatic hypotension could potentially play a role in the occurrence of syncope in dapoxetine recipients. ${ }^{[26-28]}$ Orthostatic hypotension was defined according to guidelines provided by the National Institutes of Health (NIH) in the Joint National Committee for Prevention, Detection, Evaluation, and Treatment of High Blood Pressure (JNC-7) proceed- ings. ${ }^{[32]}$ Orthostatic hypotension was considered present with a supine to standing BP decrease of $>20 \mathrm{mmHg}$ systolic or $>10 \mathrm{mmHg}$ diastolic.

The number and percentage of subjects with orthostatic hypotension, shifts from baseline, and outliers at the time of first dose are summarized in table III. There were small differences with orthostatic hypotension and orthostatic systolic BP after dosing on the first day, but these were not statistically different across the groups. Shift analysis for orthostatic hypotension and BP comparing pre- and post-dose incidence after dosing on the first day showed no notable or consistent differences between the placebo and dapoxetine groups. Additionally, evaluation of orthostatic BP changes after dosing by category/limits of change showed that the majority of subjects in all treatment groups had diastolic BP changes $\leq 10 \mathrm{mmHg}$ and systolic BP changes of $\leq 20 \mathrm{mmHg}$, with no significant differences between the placebo and dapoxetine groups. These results indicated no evidence of an effect of dapoxetine on orthostatic blood pressure.

\section{Program-Wide Evaluation of Syncopal Events}

In response to the observation of cases of syncope in the development program for dapoxetine, a program-wide process was established to identify all cases of syncope and related events. A search of the dapoxetine clinical database for all verbatim terms and MedDRA preferred terms (such as syncope, presyncope, or feeling faint) identified 37 cases of interest. A treatmentblinded committee of external experts in cardiovascular medicine, after review of blinded patient narratives, adjudicated whether a case of interest represented a true syncopal event per the medical definition of "a sudden loss of consciousness associated with the inability to maintain postural tone, followed by spontaneous recovery."'[33] Additional data were collected to evaluate the incidence, temporal relationship to dosing, etiology, and sequelae of these syncope events.

All adjudicated syncope cases and cases of interest were evaluated by treatment group and drug exposure in phases I through to III of the 
Table II. Incidence of Holter monitoring abnormalities at the time of first dose in three phase III studies

\begin{tabular}{|c|c|c|c|}
\hline \multirow[t]{2}{*}{ Holter monitoring abnormality ${ }^{a}$} & \multicolumn{3}{|c|}{ Treatment group $\left\{\mathrm{n}(\%)[95 \% \mathrm{Cl}]^{\mathrm{b}}\right\}$} \\
\hline & $\begin{array}{l}\text { placebo } \\
(\mathrm{n}=950)\end{array}$ & $\begin{array}{l}\text { dapoxetine } 30 \mathrm{mg} \\
(\mathrm{n}=715)\end{array}$ & $\begin{array}{l}\text { dapoxetine } 60 \mathrm{mg} \\
(\mathrm{n}=1688)\end{array}$ \\
\hline \multicolumn{4}{|l|}{ Ventricular ectopy } \\
\hline single & $205(21.6)[19,24.33]$ & $162(22.7)[19.64,25.91]$ & $408(24.2)[22.14,26.29]$ \\
\hline couplets & $15(1.6)[0.89,2.59]$ & $13(1.8)[0.97,3.09]$ & $28(1.7)[1.1,2.39]$ \\
\hline ventricular runs ${ }^{\mathrm{C}}$ & $5(0.5)[0.17,1.22]$ & $3(0.4)[0.09,1.22]$ & $8(0.5)[0.2,0.93]$ \\
\hline ventricular tachycardia $^{d}$ & $2(0.2)[0.03,0.76]$ & $2(0.3)[0.03,1]$ & $5(0.3)[0.1,0.69]$ \\
\hline \multicolumn{4}{|l|}{ Supraventricular ectopy } \\
\hline single & 389 (40.9) $[37.8,44.15]$ & $307(42.9)[39.27,46.66]$ & $810(48)[45.58,50.4]$ \\
\hline couplets & $32(3.4)[2.32,4.72]$ & $34(4.8)[3.32,6.58]$ & $92(5.5)[4.42,6.64]$ \\
\hline supraventricular runs ${ }^{c}$ & $22(2.3)[1.46,3.49]$ & $18(2.5)[1.5,3.95]$ & $49(2.9)[2.16,3.82]$ \\
\hline \multicolumn{4}{|l|}{ Heart rate } \\
\hline maximum heart rate $>130 \mathrm{bpm}$ & $75(7.9)[6.26,9.8]$ & $55(7.7)[5.85,9.9]$ & $70(4.1)[3.25,5.21]$ \\
\hline minimum heart rate $<40 \mathrm{bpm}$ & $20(2.1)[1.29,3.23]$ & $12(1.7)[0.87,2.91]$ & $31(1.8)[1.25,2.6]$ \\
\hline \multicolumn{4}{|l|}{ RR interval } \\
\hline longest RR interval >2 sec & $17(1.8)[1.05,2.85]$ & $18(2.5)[1.5,3.95]$ & $21(1.2)[0.77,1.9]$ \\
\hline \multicolumn{4}{|l|}{ AV block } \\
\hline 1st degree (pulse rate $>200 \mathrm{msec}$ ) & $12(1.2)[0.65,2.17]$ & $12(1.7)[0.86,2.87]$ & $23(1.3)[0.85,2.01]$ \\
\hline 2nd degree (type I) & $2(0.2)[0.03,0.76]$ & 0 & $1(0.1)[0,0.33]$ \\
\hline 2nd degree (type II) & 0 & 0 & 0 \\
\hline \multicolumn{4}{|l|}{ Conduction abnormalities } \\
\hline RBBB & $7(0.7)[0.3,1.51]$ & $8(1.1)[0.48,2.19]$ & $8(0.5)[0.2,0.93]$ \\
\hline LBBB & $1(0.1)[0,0.59]$ & 0 & $1(0.1)[0,0.33]$ \\
\hline IVCD & 0 & 0 & $1(0.1)[0,0.33]$ \\
\hline Atrial fibrillation & $3(0.3)[0.07,0.92]$ & $6(0.8)[0.31,1.8]$ & $7(0.4)[0.17,0.85]$ \\
\hline Atrial flutter & 0 & 0 & 0 \\
\hline \multicolumn{4}{|c|}{$\begin{array}{l}\text { a Incidence is based on the number of subjects experiencing each event. Each subject is counted only once in each category, regardless } 0 \\
\text { number of events in the subject. Results include three phase III studies. }{ }^{[26-28]}\end{array}$} \\
\hline \multicolumn{4}{|c|}{ b Two-sided 95\% confidence intervals using exact confidence interval method. } \\
\hline \multicolumn{4}{|l|}{$c \geq 3$ consecutive beats. } \\
\hline \multicolumn{4}{|c|}{ d $\geq 3$ consecutive ventricular beats, $\geq 100 \mathrm{bpm}$. } \\
\hline
\end{tabular}

$\mathbf{A V}=$ atrioventricular; $\mathbf{b p m}=$ beats per minute; $\mathbf{I V C D}=$ interventricular conduction defect; $\mathbf{L B B B}=$ left bundle branch block; $\mathbf{R B B B}=$ right bundle branch block.

clinical program. The highest incidence of syncopal events was reported in the phase I studies, and this was considered likely to be due to studyrelated precipitating factors (e.g. venipuncture). Incidence during phase I-III studies was summarized by whether the event occurred predose or after the administration of blinded study drug (table IV), and whether the event occurred with the first or subsequent dose, and with on-site or off-site dosing (table V). A dose-response relationship for syncope is suggested based on subject incidence across all studies, and the results sug- gested that on-site (compared with off-site) drug administration and initial (compared with subsequent) dosing on day 1 were associated with an increased incidence of syncope, although differences were not statistically significant. In phase III studies, various on-site procedures on day 1 , such as vital sign measurements, orthostatic maneuvers and ECG/Holter recordings, were performed and these procedures may have contributed to the higher on-site incidence of syncope.

Based on the judgment of the adjudication committee, the percentage of subjects with syn- 
cope resulting in loss of consciousness in the phase III placebo-controlled studies was low and dose related, but was similar for the placebo (1 of 1857 [0.05\%]) and dapoxetine $30 \mathrm{mg}$ (1 of 1616 [0.06\%]) groups, although higher in the dapoxetine $60 \mathrm{mg}$ group (6 of 2608 [0.23\%]).

Simple modifiable risk factors, such as adequate hydration and implementation of prevention maneuvers, can effectively minimize syncope occurrence. ${ }^{[34,35]}$ In order to reduce the likelihood of syncope occurrence in the late phase of the dapoxetine development program, patient in- structions were introduced into the then-ongoing phase I and III clinical studies to educate patients regarding the possibility of prodromal symptoms and to provide instruction on appropriate actions to be taken in order to prevent progression of such symptoms to actual loss of consciousness. No new cases of syncope were reported in the 1175 subjects who received dapoxetine treatment (of which 367 were newly randomized and received their first dose) after the implementation of these instructions and removal of orthostatic maneuvers from the study designs.

Table III. Incidence of orthostatic hypotension (JNC-7 criteria ${ }^{\mathrm{a}}$ ), shifts from baseline, and outliers at the time of first dose in three phase III studies

\begin{tabular}{|c|c|c|c|}
\hline \multirow[t]{2}{*}{ Measurement ${ }^{\mathrm{b}}$} & \multicolumn{3}{|c|}{ Treatment group $\left\{\mathrm{n} / \mathrm{N}(\%)[95 \% \mathrm{Cl}]^{\mathrm{c}}\right\}$} \\
\hline & placebo & dapoxetine $30 \mathrm{mg}$ & dapoxetine $60 \mathrm{mg}$ \\
\hline \multicolumn{4}{|c|}{ Orthostatic hypotension ${ }^{\mathrm{a}}$} \\
\hline Baseline & $12 / 819(1.5)[0.76,2.55]$ & $11 / 571(1.9)[0.97,3.42]$ & $40 / 1566(2.6)[1.83,3.46]$ \\
\hline Day 1 (postdose) & $71 / 821(8.6)[6.82,10.78]$ & $55 / 577(9.5)[7.26,12.23]$ & $163 / 1565(10.4)[8.95,12.04]$ \\
\hline Shift from baseline ${ }^{d}$ & $68 / 815(8.3)[6.54,10.46]$ & $48 / 566(8.5)[6.32,11.09]$ & $148 / 1556(9.5)[8.1,11.08]$ \\
\hline \multicolumn{4}{|c|}{ Orthostatic diastolic blood pressure ${ }^{a}$} \\
\hline Baseline & $9 / 819(1.1)[0.5,2.08]$ & $5 / 571(0.9)[0.28,2.03]$ & $25 / 1566(1.6)[1.04,2.35]$ \\
\hline Day 1 (postdose) & $48 / 821(5.8)[4.34,7.68]$ & $32 / 577(5.5)[3.82,7.74]$ & $93 / 1565(5.9)[4.82,7.23]$ \\
\hline Shift from baseline ${ }^{d}$ & $47 / 815(5.8)[4.27,7.6]$ & $30 / 566(5.3)[3.6,7.48]$ & $83 / 1556(5.3)[4.27,6.57]$ \\
\hline \multicolumn{4}{|c|}{ Change in diastolic blood pressure ${ }^{\mathrm{e}}$} \\
\hline$\geq-10$ & $774 / 822(94.2)[92.33,95.66]$ & $549 / 581(94.5)[92.31,96.2]$ & $1481 / 1574(94.1)[92.81,95.2]$ \\
\hline-20 to -10 & $41 / 822(5)[3.6,6.71]$ & $26 / 581(4.5)[2.94,6.49]$ & $87 / 1574(5.5)[4.45,6.77]$ \\
\hline-30 to -20 & $6 / 822(0.7)[0.27,1.58]$ & $5 / 581(0.9)[0.28,2]$ & $5 / 1574(0.3)[0.1,0.74]$ \\
\hline-50 to -30 & $1 / 822(0.1)[0,0.68]$ & $1 / 581(0.2)[0,0.96]$ & $1 / 1574(0.1)[0,0.35]$ \\
\hline \multicolumn{4}{|c|}{ Orthostatic systolic blood pressure ${ }^{a}$} \\
\hline Baseline & $5 / 820(0.6)[0.2,1.42]$ & $8 / 571(1.4)[0.61,2.74]$ & $19 / 1566(1.2)[0.73,1.89]$ \\
\hline Day 1 (postdose) & $32 / 821(3.9)[2.68,5.46]$ & $28 / 577(4.9)[3.25,6.94]$ & $91 / 1565(5.8)[4.71,7.09]$ \\
\hline Shift from baseline ${ }^{d}$ & $32 / 816$ (3.9) $[2.7,5.49]$ & $24 / 566$ (4.2) [2.74, 6.24] & $86 / 1556(5.5)[4.44,6.78]$ \\
\hline \multicolumn{4}{|c|}{ Change in systolic blood pressure ${ }^{e}$} \\
\hline$\geq-20$ & 790/822 (96.1) [94.55, 97.32] & $553 / 581(95.2)[93.11,96.77]$ & $1483 / 1574(94.2)[92.95,95.32]$ \\
\hline-30 to -20 & $27 / 822$ (3.3) [2.18, 4.74] & $23 / 581(4)[2.53,5.88]$ & $81 / 1574(5.1)[4.11,6.36]$ \\
\hline-40 to -30 & $3 / 822(0.4)[0.08,1.06]$ & $3 / 581(0.5)[0.11,1.5]$ & $9 / 1574(0.6)[0.26,1.08]$ \\
\hline-50 to -40 & $1 / 822(0.1)[0,0.68]$ & $1 / 581(0.2)[0,0.96]$ & $0 / 1574(0)[0,0.23]$ \\
\hline-70 to -50 & $1 / 822(0.1)[0,0.68]$ & $1 / 581(0.2)[0,0.96]$ & $1 / 1574(0.1)[0,0.35]$ \\
\hline \multicolumn{4}{|c|}{$\begin{array}{l}\text { Orthostatic hypotension defined by the Joint National Committee for Prevention, Detection, Evaluation, and Treatment of High Blood } \\
\text { Pressure (JNC-7) criteria as a supine to standing blood pressure decrease of }>20 \mathrm{mmHg} \text { systolic or }>10 \mathrm{mmHg} \text { diastolic. }\end{array}$} \\
\hline \multicolumn{4}{|c|}{$\begin{array}{l}\text { b Baseline measurement was } 15 \text { minutes predose; postdose measurement was anytime at 1, 1.5, 2, and } 3 \text { hours postdose. Results include } \\
\text { three phase III studies. }{ }^{[26-28]}\end{array}$} \\
\hline \multicolumn{4}{|c|}{ c Two-sided 95\% confidence intervals using exact confidence interval method. } \\
\hline \multicolumn{4}{|c|}{ d Subjects who met JNC-7 criteria at day 1 postdose but not at baseline. } \\
\hline \multicolumn{4}{|c|}{ y iposicuse. } \\
\hline
\end{tabular}


Table IV. Subjects with syncope before (predose) and after administration of dapoxetine by dose group in phase I-III dapoxetine studies

\begin{tabular}{|c|c|c|}
\hline Syncope cases by treatment & Subjects treated $(\mathrm{N})$ & Subjects with event $\left\{\mathrm{n}(\%)[95 \% \mathrm{Cl}]^{\mathrm{a}}\right\}$ \\
\hline \multicolumn{3}{|l|}{ Adjudicated syncope $^{b}$} \\
\hline Predose & 7219 & $2(0.03)[0,0.1]$ \\
\hline \multicolumn{3}{|l|}{ Postdose } \\
\hline placebo & 2435 & $1(0.04)[0,0.23]$ \\
\hline dapoxetine $30 \mathrm{mg}$ & 1944 & $2(0.1)[0.01,0.37]$ \\
\hline dapoxetine $60 \mathrm{mg}$ & 4636 & $11(0.24)[0.12,0.42]$ \\
\hline other & 610 & $2(0.33)[0.04,1.18]$ \\
\hline \multicolumn{3}{|l|}{ Cases of interest ${ }^{\mathrm{c}}$} \\
\hline Predose & 7219 & $5(0.07)[0.02,0.16]$ \\
\hline \multicolumn{3}{|l|}{ Postdose } \\
\hline placebo & 2435 & $2(0.08)[0.01,0.3]$ \\
\hline dapoxetine $30 \mathrm{mg}$ & 1944 & $7(0.36)[0.14,0.74]$ \\
\hline dapoxetine $60 \mathrm{mg}$ & 4636 & $21(0.45)[0.28,0.69]$ \\
\hline other & 610 & $2(0.33)[0.04,1.18]$ \\
\hline \multicolumn{3}{|c|}{ a Two-sided 95\% confidence intervals using exact confidence interval method. } \\
\hline \multicolumn{3}{|c|}{ b Cases adjudicated with medical definition of syncope by a blinded committee of external experts. } \\
\hline \multicolumn{3}{|c|}{ c Adverse events identified in the dapoxetine clinical database that might reflect a syncope event. } \\
\hline
\end{tabular}

\section{Discussion}

The stages of drug development from preclinical through to pivotal clinical studies provide information to characterize the cardiovascular safety of a new drug, while relevant findings from one phase may be reason to modify or expand subsequent research to evaluate certain findings. A potential signal detected during the preclinical and clinical development process may merit further investigation to establish and characterize the relevance of these findings. Although the analysis typically occurs in a sequential fashion, in line with the traditional stages of drug development, the final assessment of the cardiovascular safety of a drug requires an integration and synthesis of all information garnered throughout the research and development programs.

The cardiovascular safety profile of dapoxetine was investigated during the premarketing evaluation of the medication. Dapoxetine is an SSRI and, as a new compound in this class, it merited special attention, given that other SSRI medications approved for the treatment of depression, anxiety, and other psychiatric conditions have infrequently been associated with reports of cardiovascular adverse events. ${ }^{[14-16]}$ It was also important to assess the cardiovascular safety profile of dapoxetine because the proposed indication (i.e. PE) is not a life-threatening condition, and so syncope, albeit rare, might offset the clinical benefit.

The findings of preclinical safety pharmacology studies suggested that adverse electrophysiologic or hemodynamic effects are unlikely at the concentrations of dapoxetine achieved with recommended doses (section 2). Phase I clinical pharmacology studies showed that dapoxetine did not prolong the QT/QTc interval and had no clinically significant electrocardiographic effects, with no evidence of delayed repolarization or conduction effects (section 3). Phase III clinical studies of dapoxetine in men with PE indicated that dapoxetine treatment was generally safe and well tolerated with the recommended dosing regimens of 30 and $60 \mathrm{mg}$ as required (section 5).

Extensive analyses were conducted to investigate the etiology and factors predisposing to the occurrence of syncope in the dapoxetine clinical program (section 6). It was noted that the majority of syncopal events across the entire dapoxetine program occurred during study visits (on site) on day 1 following administration of the first dose when various study-related procedures, 
such as vital signs measurements, orthostatic maneuvers, ECG/Holter recordings (in phase III studies), and venipunctures (in phase I studies) were performed. These procedures may have contributed to the incidence of syncope, as these and similar factors are known to contribute to or trigger vasovagal syncope. ${ }^{[36-39]}$

Serotonin mediates BP control through both afferent and efferent serotonergic pathways, and alteration of serotonergic pathways can provoke or prevent a vasovagal response. ${ }^{[37,40,41]}$ The principal action that leads to hypotension and bradycardia in neurocardiogenic syncope appears to be sudden and profound sympathetic withdrawal. ${ }^{[41]}$ In a tilt-testing study in humans, clomipramine, which has serotonin reuptake inhibitory activity, was found to provoke such a vasovagal response, suggesting a role of serotonin in cardiac regulation. ${ }^{[42]} \mathrm{A}$ similar form of sympathetic withdrawal has been reported in an animal model following injection of serotonin into the intracerebral ventricular areas, suggesting that acute changes in serotonin may act at a central level to inhibit sympathetic activity, and that the vasodilatation and bradycardia seen during neurocardiogenic syncope may have a central serotonergic component. ${ }^{[43]}$ Thus, agents that influence serotonergic activity may contribute to a vasovagal response, indicating that a vasovagal (neurocardiogenic) mechanism appears to be the most likely etiology of syncope reported in the dapoxetine development.

An extensive assessment of dapoxetine did not reveal any other significant cardiovascular ad- verse events, although such events have been associated with other antidepressant SSRIs. For instance, prescribing information for antidepressant SSRIs report that during premarketing clinical studies, adverse events such as hypertension, tachycardia, palpitations, and chest pain were observed frequently. ${ }^{[17-19]}$ This pattern of findings suggests that cardiovascular safety issues may not be generalizable across the SSRI class of drugs, and one reason for this may relate to differences between each of the SSRI's pharmacokinetic characteristics. ${ }^{[17-19]}$ Dapoxetine demonstrates rapid absorption and elimination, reaching $\mathrm{C}_{\max }$ within 1.5 hours of administration, plasma concentrations are less than $5 \%$ of peak at 24 hours, and there is minimal accumulation following daily dosing. ${ }^{[7-9]}$ In comparison, other SSRI medications have relatively slower absorption, and lack the rapid initial elimination phase that is a characteristic of dapoxetine, resulting in potentially longer periods of exposure and accumulation. ${ }^{[8,24,44,45]}$

The premarketing evaluation of dapoxetine provided a comprehensive assessment of the cardiovascular safety of dapoxetine. However, there are potential limitations on the sensitivity of the premarketing studies related to study design, such as the number of subjects treated and the duration of treatment. In addition, the premarketing findings are limited due to the lack of long-term safety data on cardiovascular endpoints, such as myocardial infarction, death, revascularization, as well as surrogate endpoints, such as inflammation and platelet aggregation. The dapoxetine

Table V. Subjects with syncope at first or subsequent doses and at on-site or off-site dosing in phase I-III dapoxetine studies

\begin{tabular}{|c|c|c|c|c|}
\hline \multirow[t]{2}{*}{ Syncope cases by dosing } & \multicolumn{2}{|l|}{ On-site dosing } & \multicolumn{2}{|l|}{ Off-site dosing } \\
\hline & subjects treated $(\mathrm{N})$ & $\begin{array}{l}\text { subjects with event } \\
\left\{\mathrm{n}(\%)[95 \% \mathrm{Cl}]^{\mathrm{a}}\right\}\end{array}$ & subjects treated $(\mathrm{N})$ & $\begin{array}{l}\text { subjects with event } \\
\left\{\text { n }(\%)[95 \% \mathrm{CI}]^{\mathrm{a}}\right\}\end{array}$ \\
\hline \multicolumn{5}{|l|}{ Adjudicated syncope ${ }^{b}$} \\
\hline First dose & 3568 & $10(0.28)[0.135,0.515]$ & 2171 & $1(0.046)[0.001,0.256]$ \\
\hline Subsequent dose & 557 & $1(0.18)[0.005,0.996]$ & 4686 & $3(0.06)[0.013,0.187]$ \\
\hline \multicolumn{5}{|l|}{ Cases of interest $^{c}$} \\
\hline First dose & 3566 & $15(0.42)[0.236,0.693]$ & 2171 & $1(0.046)[0.001,0.256]$ \\
\hline Subsequent dose & 557 & $9(1.62)[0.741,3.045]$ & 4686 & $5(0.11)[0.035,0.249]$ \\
\hline \multicolumn{5}{|c|}{ a Two-sided 95\% confidence intervals using exact confidence interval method. } \\
\hline \multicolumn{5}{|c|}{ b Cases adjudicated with medical definition of syncope by a blinded committee of external experts. } \\
\hline \multicolumn{5}{|c|}{ c Adverse events identified in the dapoxetine clinical database that might reflect a syncope event. } \\
\hline
\end{tabular}


research and development program includes ongoing long-term postmarketing and phase III clinical studies, and so our understanding of the cardiovascular safety of dapoxetine will continue to evolve with the integration and synthesis of relevant new information.

In conclusion, findings of the dapoxetine development program indicate no associated significant cardiovascular adverse events, except for vasovagal-mediated (neurocardiogenic) syncope. The incidence of syncope, albeit rare, should be considered as part of the benefit/risk analysis with the proposed indication (i.e. PE).

\section{Acknowledgments}

Johnson \& Johnson Pharmaceutical Research \& Development, L.L.C., provided funding for the design and conduct of the dapoxetine clinical studies discussed in this article, including collection, management, and analysis of the data. Dr Peter Kowey provided fee-for-service consultation to Johnson \& Johnson Pharmaceutical Research \& Development during the development for dapoxetine. He did not serve as an investigator and did not otherwise participate in any of the clinical trials. He received no compensation for time spent in the preparation of this article. Dr Peter Kowey holds no equity interest in Johnson \& Johnson or in any other pharmaceutical company. Drs Peter DiBattiste, Ramagopal Mudumbi, and Joseph W. Aquilina are employees of Johnson \& Johnson Pharmaceutical Research \& Development and own stock in Johnson \& Johnson. All authors met ICMJE criteria and all those who fulfilled those criteria are listed as authors. Bradford Challis, PhD, an employee of Johnson \& Johnson Pharmaceutical Research \& Development, provided editorial support for the article.

\section{References}

1. American Psychiatric Association. Diagnostic and statistical manual of mental disorders. 4th ed. Washington, DC: American Psychiatric Association, 2000

2. McMahon CG, Althof SE, Waldinger MD, et al. An evidence-based definition of lifelong premature ejaculation: report of the International Society for Sexual Medicine (ISSM) ad hoc committee for the definition of premature ejaculation. J Sex Med 2008 Jul; 5 (7): 1590-606

3. Jackson G, Rosen RC, Kloner RA, et al. The second Princeton consensus on sexual dysfunction and cardiac risk: new guidelines for sexual medicine. J Sex Med 2006 Jan; 3 (1): 28-36

4. Basile Fasolo C, Mirone V, Gentile V, et al. Premature ejaculation: prevalence and associated conditions in a sample of 12,558 men attending the andrology prevention week 2001 - a study of the Italian Society of Andrology (SIA). J Sex Med 2005 May; 2 (3): 376-82

5. Public assessment report scientific discussion: priligy dapoxetine hydrochloride film-coated tablets, 30 and $60 \mathrm{mg}$.
Läkemedelsverket Medical Products Agency, December 2008. Available from URL: http://www.lakemedelsverket. se/SPC_PIL/Pdf/par/Priligy\%20film\%20coated\%20tablets\% 2030\% 20 and\%2060\%20mg.pdf [Accessed 2011 Jan 7]

6. McMahon CG. Dapoxetine for premature ejaculation. Expert Opin Pharmacother 2010 Jul; 11 (10): 1741-52

7. Dresser MJ, Kang D, Staehr P, et al. Pharmacokinetics of dapoxetine, a new treatment for premature ejaculation: impact of age and effects of a high-fat meal. J Clin Pharmacol 2006 Sep; 46 (9): 1023-9

8. Modi NB, Dresser MJ, Simon M, et al. Single- and multipledose pharmacokinetics of dapoxetine hydrochloride, a novel agent for the treatment of premature ejaculation. J Clin Pharmacol 2006 Mar; 46 (3): 301-9

9. Thyssen A, Sharma O, Tianmei S, et al. Pharmacokinetics of dapoxetine hydrochloride in healthy chinese, Japanese, and caucasian men. J Clin Pharmacol 2010 Dec; 50 (12): 1450-60

10. Montejo AL, Llorca G, Izquierdo JA, et al. Incidence of sexual dysfunction associated with antidepressant agents: a prospective multicenter study of 1022 outpatients. Spanish Working Group for the Study of Psychotropic-Related Sexual Dysfunction. J Clin Psychiatry 2001; 62 Suppl. 3: 10-21

11. Montejo-Gonzalez AL, Llorca G, Izquierdo JA, et al. SSRIinduced sexual dysfunction: fluoxetine, paroxetine, sertraline, and fluvoxamine in a prospective, multicenter, and descriptive clinical study of 344 patients. J Sex Marital Ther 1997 Fall; 23 (3): 176-94

12. Giuliano F, Hellstrom WJ. The pharmacological treatment of premature ejaculation. BJU Int 2008 Sep; 102 (6): 668-75

13. Montague DK, Jarow J, Broderick GA, et al. AUA guideline on the pharmacologic management of premature ejaculation. J Urol 2004 Jul; 172 (1): 290-4

14. Goldstein BJ, Goodnick PJ. Selective serotonin reuptake inhibitors in the treatment of affective disorders: III. Tolerability, safety and pharmacoeconomics. J Psychopharmacol 1998; 12 (3 Suppl. B): S55-87

15. Pacher P, Kecskemeti V. Cardiovascular side effects of new antidepressants and antipsychotics: new drugs, old concerns? Curr Pharm Des 2004; 10 (20): 2463-75

16. Swenson JR, Doucette S, Fergusson D. Adverse cardiovascular events in antidepressant trials involving high-risk patients: a systematic review of randomized trials. Can J Psychiatry 2006 Dec; 51 (14): 923-9

17. ZOLOFT (sertraline hydrochloride) [prescribing information]. New York (NY): Pfizer Inc, 2008

18. PAXIL (paroxetine hydrochloride) [prescribing information]. Research Triangle Park (NC): GlaxoSmithKline, 2009

19. PROZAC (fluoxetine hydrochloride) [prescribing information]. Indianapolis (IN): Eli Lilly and Co, 2009

20. US Food and Drug Administration. Preliminary concept paper on the clinical evaluation of the QT/QTc interval prolongation and proarrhythmic potential for non-antiarrhythmic drugs; 15 November 2002. Available from URL: http://www.fda.gov/ohrms/dockets/ac/03/briefing/pubs\% 5Cprelim.pdf [Accessed 2010 Aug 2]

21. ICH harmonized tripartite guideline E2a. Clinical safety data management: definitions and standards for expedited reporting; 27 October 1994. Available from URL: http:// www.ich.org/LOB/media/MEDIA436.pdf [Accessed 2010 Aug 2] 
22. ICH Harmonized Tripartite Guideline S7A. Safety pharmacology studies for human pharmaceuticals; 8 November 2000. Available from URL: http://www.ich.org/LOB $/ \mathrm{me}$ dia/MEDIA504.pdf [Accessed 2010 Aug 2]

23. ICH Harmonized Tripartite Guideline S7B. The non-clinical evaluation of the potential for delayed ventricular repolarization (QT interval prolongation) by human pharmaceuticals; 12 May 2005. Available from URL: http:// www.ich.org/LOB/media/MEDIA2192.pdf [Accessed 2010 Aug 2]

24. Modi NB, Nath R, Staehr P, et al. Pharmacokinetic, pharmacodynamic, and electrocardiographic effects of dapoxetine and moxifloxacin compared with placebo in healthy adult male subjects. J Clin Pharmacol 2009 Jun; 49 (6): 634-42

25. Nilsson-Neijber A, Althof S, Gittelman M, et al. Dapoxetine treatment of men with premature ejaculation: dose-finding analysis [abstract no. P-02-163]. J Sex Med 2006; Suppl. 3: 224-86. Plus poster presented at 8th Congress of the European Society for Sexual Medicine; 2005 Dec 4-7; Copenhagen

26. Buvat J, Tesfaye F, Rothman M, et al. Dapoxetine for the treatment of premature ejaculation: results from a randomized, double-blind, placebo-controlled phase 3 trial in 22 countries. Eur Urol 2009; 55 (4): 957-67

27. Kaufman JM, Rosen RC, Mudumbi RV, et al. Treatment benefit of dapoxetine for premature ejaculation: results from a placebo-controlled phase III trial. BJU Int 2009 Mar; 103 (5): 651-8

28. McMahon C, Kim SW, Park NC, et al. Treatment of premature ejaculation in the Asia-Pacific region: results from a phase III double-blind, parallel-group study of dapoxetine. J Sex Med 2010 Jan; 7 (1 Pt 1): 256-68

29. Pryor JL, Althof SE, Steidle C, et al. Efficacy and tolerability of dapoxetine in treatment of premature ejaculation: an integrated analysis of two double-blind, randomised controlled trials. Lancet 2006 Sep 9; 368 (9539): 929-37

30. Shabsigh R, Patrick DL, Rowland DL, et al. Perceived control over ejaculation is central to treatment benefit in men with premature ejaculation: results from phase III trials with dapoxetine. BJU Int 2008 Sep; 102 (7): 824-8

31. Ng GA. Treating patients with ventricular ectopic beats. Heart 2006 Nov; 92 (11): 1707-12

32. National High Blood Pressure Education Program. The Seventh Report of the Joint National Committee on Prevention, Detection, Evaluation, and Treatment of High Blood Pressure. AV Chobanian (chair). U.S. Department of Health and Human Services, National Institutes of Health-National Heart, Lung, and Blood Institute; National High Blood Pressure Education Program. NIH Publication No. 04-5230. August 2004. Available from URL: http://www.nhlbi.nih.gov/guidelines/hypertension/jnc7full. pdf [Accessed 2011 Jan 7]

33. Soteriades ES, Evans JC, Larson MG, et al. Incidence and prognosis of syncope. N Engl J Med 2002 Sep 19; 347 (12): 878-85

34. Brignole M, Alboni P, Benditt DG, et al. Guidelines on management (diagnosis and treatment) of syncope-update 2004: executive summary. Eur Heart J 2004 Nov; 25 (22): 2054-72

35. Chen L, Chen MH, Larson MG, et al. Risk factors for syncope in a community-based sample (the Framingham Heart Study). Am J Cardiol 2000 May 15; 85 (10): 1189-93

36. Chen-Scarabelli C, Scarabelli TM. Neurocardiogenic syncope. BMJ 2004 Aug 7; 329 (7461): 336-41

37. Grubb BP. Clinical practice: neurocardiogenic syncope. N Engl J Med 2005 Mar 10; 352 (10): 1004-10

38. Mosqueda-Garcia R, Furlan R, Tank J, et al. The elusive pathophysiology of neurally mediated syncope. Circulation 2000 Dec 5; 102 (23): 2898-906

39. Robertson RM, Medina E, Shah N, et al. Neurally mediated syncope: pathophysiology and implications for treatment. Am J Med Sci 1999 Feb; 317 (2): 102-9

40. Grubb BP. Neurocardiogenic syncope and related disorders of orthostatic intolerance. Circulation 2005 Jun 7; 111 (22): 2997-3006

41. Grubb BP, Karas BJ. The potential role of serotonin in the pathogenesis of neurocardiogenic syncope and related autonomic disturbances. J Interv Card Electrophysiol 1998 Dec; 2 (4): 325-32

42. Theodorakis GN, Livanis EG, Leftheriotis D, et al. Head-up tilt test with clomipramine challenge in vasovagal syndrome: a new tilt testing protocol. Eur Heart J 2003 Apr; 24 (7): 658-63

43. Abboud FM. Neurocardiogenic syncope. N Engl J Med 1993 Apr 15; 328 (15): 1117-20

44. Giuliano F. 5-Hydroxytryptamine in premature ejaculation: opportunities for therapeutic intervention. Trends Neurosci 2007 Feb; 30 (2): 79-84

45. Hiemke C, Hartter S. Pharmacokinetics of selective serotonin reuptake inhibitors. Pharmacol Ther 2000 Jan; 85 (1): $11-28$

Correspondence: Dr Peter R. Kowey, Division of Cardiovascular Disease, Lankenau Hospital and Institute of Medical Research, LH MOB East, Suite 556, 100 Lancaster Avenue, Wynnewood, PA 19096, USA.

E-mail: KoweyP@MLHS.ORG 